Article

\title{
Improved Shear Strength Equation for Concrete Wide Beams
}

\author{
Min Sook Kim ${ }^{1}{ }^{(\mathbb{D}}$, Joowon Kang ${ }^{2}$ and Young Hak Lee ${ }^{1, *(\mathbb{C}}$ \\ 1 Department of Architectural Engineering, Kyung Hee University, Deogyeong-Daero 1732, Yongin 17104, \\ Korea; kimminsook@khu.ac.kr \\ 2 School of Architecture, Yeungnam University, 280 Daehak-Ro, Gyeongsan, Gyeongbuk 38541, Korea; \\ kangj@ynu.ac.kr \\ * Correspondence: leeyh@khu.ac.kr; Tel.: +82-31-201-3815
}

Received: 31 August 2019; Accepted: 20 October 2019; Published: 24 October 2019

check for updates

Featured Application: This study provides a reasonable method to predict shear strength for concrete wide beams.

\begin{abstract}
An improved shear strength equation is proposed that considers transverse reinforcement spacing and support conditions for concrete wide beams. Eighteen specimens were fabricated to examine the influence of transverse reinforcement spacing, the number of transverse shear reinforcement, and support width on shear capacity. From the test results, a shear strength equation is proposed and used to evaluate the shear strength of 23 specimens from previous studies and 18 from this study. For the 41 specimens, the proposed shear strength equation results had a mean of 1.16 and a standard deviation of 0.16 . It showed that the proposed shear strength equation can predict shear strength reasonably well for concrete wide beams.
\end{abstract}

Keywords: shear reinforcement; shear strength; reinforced concrete; wide beam; transverse shear reinforcement spacing

\section{Introduction}

Concrete wide beams are used in commercial facilities, parking lots, and warehouses mainly to reduce story height. The stirrup legs are normally placed around the outermost longitudinal reinforcement for shear reinforcement. A lack of shear reinforcement across the web of the beam can lead to a concentration of diagonal compressive stresses. In addition, for beams with greater width than the support, they can cause different cracking patterns due to the stress concentration in the beams. Leonhardt and Walther [1] suggested that transverse reinforcement spacing should be limited to 200 $\mathrm{mm}$ to $400 \mathrm{~mm}$ depending on the shear stress. Hsiumg and Frantz [2] and Anderson and Ramirez [3] conducted several experimental studies to investigate the stress changes in concrete beams with the same width and effective depth. Hsiumg and Frantz [2] reported that the interior shear legs carry a higher shear force in the transverse direction than the exterior legs in beams with multiple stirrups, and the shear stress distribution is affected by different transverse stirrup arrangements. Anderson and Ramirez [3] noted that the shear stress distribution is dependent on different stirrup detailing, and the contribution of the main reinforcement can be determined by different stirrup details. They suggested that the stirrup legs should be distributed transversely across the web of beams. Lubell et al. [4] and Shuraim [5] tested several wide beams with different transverse reinforcement spacing, number of legs, and support widths. Their results showed that the design codes overestimate the shear capacities of wide beams because they do not consider transverse reinforcement spacing, number of legs, or support width. Mohammadyan et al. [6] tested 6 reinforced wide shallow concrete beams with diverse types of 
reinforcement to investigate the effectiveness of various types of shear reinforcement in improving the shear capacity of wide beams. The results showed that independent bent-up bars increased the shear capacity and ductility of wide beams. The combination of bent-up bars with stirrups can achieved higher shear capacity and gradual failure of wide beams. Conforti et al. [7] conducted shear tests on 14 wide shallow beams with different widths and depths to evaluate shear performance. The experimental results indicated that wide shallow beams with width-to-effective depth ratio from 2 to 3 enhanced shear behavior, and shear equations of current codes do not consider the extra resistance in shear of wide shallow beams. Also, Conforti et al. [8] evaluated the influence of width-to-effective-depth ratio $(b / d)$ and reinforcement spacing-to-effective depth ratio on the shear behavior of reinforced concrete beams without the web reinforcement. The experimental results showed that for $b / d>1$, an increase in the $b / d$ determines a non-negligible increment in the shear strength whereas the s/d does not affect the capacity. Khalil et al. [9] analyzed effect of the beam width-to-depth ratio and the column width-to-beam-width ratio. The test results presented that although the beam-width-to-depth ratio and support width has significant influence on shear performance, the predictive equations for shear strength did not take those effect into consideration which leads to a major error in estimating the shear strength of wide shallow beams. A modified formula was proposed to predict the effective width accurately based on statistical procedure.

In addition to evaluating the effect of design parameters on the shear capacity for concrete wide beams, recent studies have been conducted to add fiber to concrete. Several authors have performed experiment to determine the shear contribution provided by polypropylene fibers in slender beams. Conforti et al. [10] showed that macro-synthetic fibers can be used as a shear reinforcement in wide shallow beams based on experimental programs. Navas et al. [11] performed the test on 16 full-scale specimens. The results indicated that the fibers showed significantly improved shear strength in the reinforced concrete beams.

The main objective of this paper is to propose a shear strength equation that considers transverse reinforcement spacing, the number of shear legs, and support conditions applicable to both plate type and stirrup shear reinforcement. Shear tests were performed on 18 concrete wide beam specimens embedded with shear reinforcement plates as described by Kim et al. [12] to determine a shear strength equation. The equation was compared with the test results, current ACI provisions, and another equation suggested by Lubell et al. [4] and Shuraim [5].

\section{Shear Strength Equation}

\subsection{ACI Building Code (ACI 318-14)}

The shear strength equation in ACI 318-14 [13] is calculated using the sum of the concrete's shear strength and the shear reinforcement, as shown in Equations (1)-(3).

$$
\begin{gathered}
V_{n, A C I}=V_{c, A C I}+V_{s, A C I} \\
V_{c, A C I}=\frac{1}{6} \sqrt{f^{\prime}{ }_{c}} b_{w} d \\
V_{s, A C I}=\frac{A_{s} f_{y v} d}{s_{L}}
\end{gathered}
$$

where $V_{n, A C I}$ is the nominal shear strength, and $V_{c, A C I}, V_{s, A C I}$ are the shear strength of concrete and the shear reinforcement, respectively. The shear strength of concrete as shown in Equation (2) can be obtained using the compressive strength of concrete $\left(f^{\prime}{ }_{c}\right)$, beam width $\left(b_{w w}\right)$ and effective depth $(d)$. Equation (3) calculates the shear strength of the shear reinforcement materials, which includes the stirrup area $\left(A_{s}\right)$, the stirrup's yield strength $\left(f_{y v}\right)$, effective beam depth $(d)$ and the longitudinal spacing of the stirrups $\left(s_{L}\right)$. 


\subsection{Modified ACI Building Code (Kim et al. [12])}

Kim et al. [12] proposed a shear strength equation for concrete beams with shear reinforced FRP plates by modifying the ACI318-11 shear strength equation [11]. Plate type shear reinforcement consists of horizontal and vertical strips, as shown in Figure 1. Kim et al. [12] reported that the horizontal components of the plate did not contribute significantly enough to the shear strength. Based on this investigation, the shear strength equation by Kim et al. [12] only considered vertical components and used Equation (4) to calculate the cross-sectional area of the FRP reinforcement.

$$
A_{s}=n w_{f} t_{f}
$$

where $n$ is number of the GFRP and steel plate vertical components, $w_{f}$ is the width of the GFRP and steel plate and $t_{f}$ is the thickness of the GFRP and steel plate.

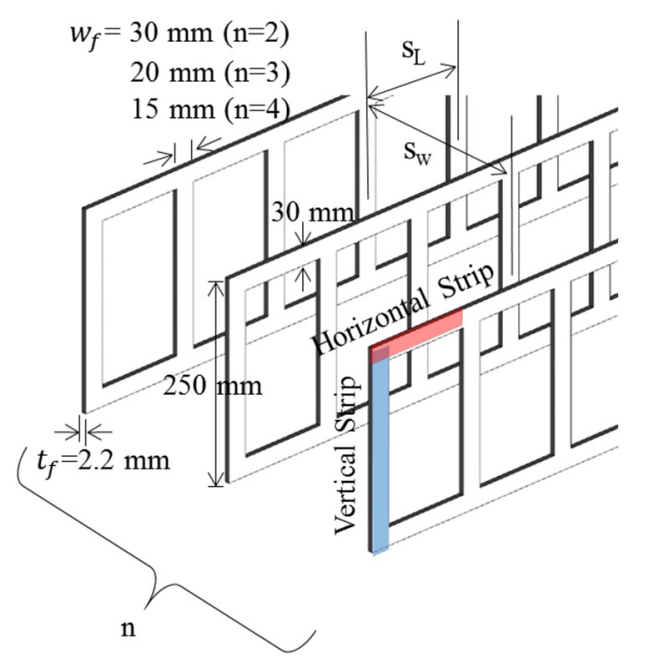

$$
\begin{aligned}
& n \text { : number of the vertical component of the steel plate } \\
& s_{L}: \text { center-to-center longitudinal spacing of shear reinforcement }(\mathrm{mm}) \\
& s_{w}: \text { center-to-center transverse spacing of shear reinforcement }(\mathrm{mm}) \\
& t_{f}: \text { thickness of steel plate }(\mathrm{mm}) \\
& w_{f}: \text { width of steel plate }(\mathrm{mm})
\end{aligned}
$$

Figure 1. Shape of plate type of shear reinforcement.

ACI 440.1R [14] provides a shear strength equation for concrete with FRP flexural reinforcement. However, Kim et al. [15] verified that in the case of a specimen reinforced by a plate type, substituting the tensile strength for the shear strength in the equation in ACI 318-14 is more reasonable than using the equation described in ACI 440.1R. In this paper, when considering plate type and stirrups as shear reinforcement nominal shear strength is calculated using the equation in ACI 318-14 and Kim et al., as shown in Equations (1)-(4).

\subsection{Lubell's Equation for Support Conditions}

Lubell et al. [4] studied the influence of support conditions on shear capacity in wide beams, and proposed a shear capacity reduction factor $\left(\beta_{L}\right)$ to reflect the decrease of shear capacity in accordance with support width. They proposed shear strength equations as shown in Equations (5)-(7) by multiplying the nominal shear strength calculated in ACI 318-14 by the shear capacity reduction factor, which considers the influence of support conditions.

$$
\beta_{L}=0.7+0.3 \kappa
$$




$$
\begin{gathered}
\kappa=\min \left\{\left(b_{s} / b_{w}\right) \operatorname{or}\left(c_{y} / b_{w}\right)\right\} \\
V_{n, \text { Lubell }}=\beta_{L}\left(V_{c, A C I}+V_{s, A C I}\right)
\end{gathered}
$$

where $\kappa$ is the shape function of the support width ratio. This represents the smaller of the loaded width-to-member width or supported width-to-member width ratio. $\beta_{L}$ is the reduction coefficient following the support conditions.

\subsection{Shuraim's Equation for Transverse Spacing}

Shuraim [5] proposed the shear equations shown in Equations (8)-(10). The equivalent spacing $\left(s_{e q}\right)$ replaces the longitudinal spacing $\left(s_{L}\right)$ in ACI 318-14 to consider the wide beam's decreasing shear capacity as the transverse spacing increases. Equivalent spacing was proposed by regression analysis and obtained by contribution of transverse spacing $\left(s_{w}\right)$ and longitudinal spacing $\left(s_{L}\right)$.

$$
\begin{gathered}
V_{n, \text { Shuraim }}=V_{c, A C I}+\frac{A_{s} f_{y v} d}{s_{e q}} \\
s_{e q}=\left(\frac{s_{L}}{d}\right)^{0.25} \sqrt{s_{L} s_{w}} \\
s_{w}=\left(\frac{s_{L}}{d}\right)^{0.5} d
\end{gathered}
$$

\section{Experimental Program}

\subsection{Materials}

The average compressive strengths of the 28-day concrete used for specimen fabrication was $28.8 \mathrm{MPa}$ and $35 \mathrm{MPa}$. Deformed steel bars with a $22 \mathrm{~mm}$ diameter and yield strength of $400 \mathrm{MPa}$ were used as longitudinal and column reinforcements. Hoops were fabricated with $10 \mathrm{~mm}$ diameter deformed steel bars with a yield strength of $400 \mathrm{MPa}$. Steel plates with openings as shear reinforcement were used. The yield strength and elasticity modulus of the steel plates were $402 \mathrm{MPa}$ and $200 \mathrm{GPa}$, respectively. Table 1 lists the properties of specimen materials.

Table 1. Material properties.

\begin{tabular}{cccc}
\hline & Yield Strength (MPa) & \multicolumn{2}{c}{ Modulus of Elasticity (GPa) } \\
\hline Rebar & 400 & \multicolumn{2}{c}{200} \\
Steel Plate & 402 & 200 & Maximum Aggregate \\
& Compressive Strength & Modulus of Elasticity & Size (mm) \\
\hline (MPa) & (GPa) & 25 \\
1-Concrete & 35.0 & 55 & 25 \\
\hline
\end{tabular}

\subsection{Specimen Details}

Eighteen specimens were tested to study the influence on shear capacity of transverse reinforcement spacing, the number of legs, and support conditions. The steel plates with openings were used as a shear reinforcement as shown in Figure 1. All specimens were designed with the same amount of shear reinforcement. The specimens were composed of three groups, A, B, and C, depending on their variables. Group A is transverse reinforcement spacing, and ranged from $151 \mathrm{~mm}$ to $548 \mathrm{~mm}$. Group B is the number of legs, ranging from 2 to 4 . Group $C$ specimens are for estimating the change of shear strength due to support conditions. Group C was divided into Group C1, which used the width of the column support as variable, and Group $\mathrm{C} 2$, which used the width of the support as a variable. The specimens with different numbers of legs were designed with equivalent transverse reinforcement 
spacing to independently investigate the effects of the legs. Figure 2 shows typical specimen details. Figure 3 is notations to identify each specimen. Table 2 presents the specimen details.

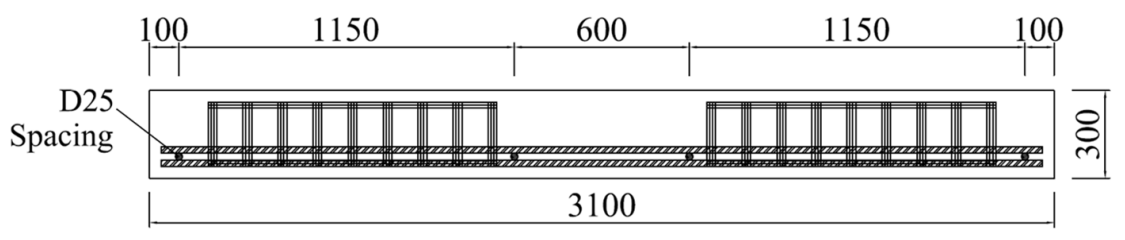

Front View

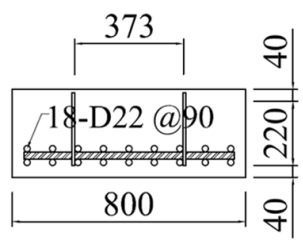

Side View

(a)

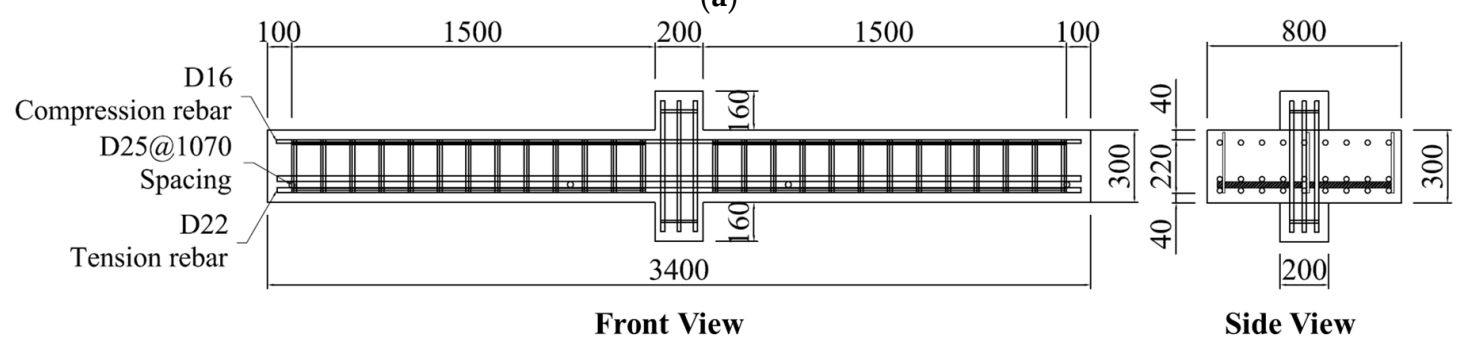

(b)

Figure 2. Details of specimens [mm]: (a) general wide beam (1S-N373); (b) wide beam with column support (1S-IC1).

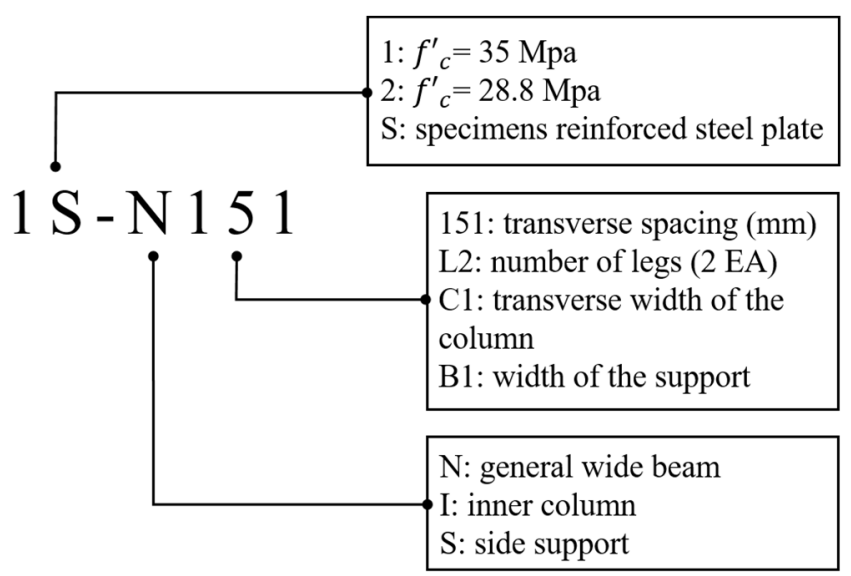

Figure 3. Notation of specimens. 
Table 2. Grouping and details of the experiment specimens.

\begin{tabular}{|c|c|c|c|c|c|c|c|c|c|c|c|c|c|}
\hline No & Group & Name & $\begin{array}{c}f_{c}^{\prime} \\
{[\mathrm{MPa}]}\end{array}$ & $\begin{array}{c}d \\
{[\mathrm{~mm}]}\end{array}$ & $n$ & $\begin{array}{c}s_{L} \\
{[\mathrm{~mm}]}\end{array}$ & $\begin{array}{c}s_{w} \\
{[\mathrm{~mm}]}\end{array}$ & $s_{w} / d$ & $\begin{array}{c}c_{x} \\
{[\mathrm{~mm}]}\end{array}$ & $\begin{array}{c}c_{y} \\
{[\mathrm{~mm}]}\end{array}$ & $\begin{array}{c}b_{s} \\
{[\mathrm{~mm}]}\end{array}$ & $\kappa$ & $\begin{array}{l}V_{n, A C I} \\
{[\mathrm{kN}]}\end{array}$ \\
\hline 1 & \multirow{7}{*}{$\begin{array}{c}\text { A } \\
\text { (Transvers spacing) }\end{array}$} & 1S-N151 & 35 & 225.5 & 2 & 120 & 151 & 0.67 & - & - & 800 & 1 & 277 \\
\hline 2 & & 1S-N199 & 35 & 225.5 & 2 & 120 & 199 & 0.88 & - & - & 800 & 1 & 277 \\
\hline 3 & & 1S-N262 & 35 & 225.5 & 2 & 120 & 262 & 1.16 & - & - & 800 & 1 & 277 \\
\hline 4 & & 1S-N321 & 35 & 225.5 & 2 & 120 & 321 & 1.42 & - & - & 800 & 1 & 277 \\
\hline 5 & & 1S-N373 & 35 & 225.5 & 2 & 120 & 373 & 1.65 & - & - & 800 & 1 & 277 \\
\hline 6 & & 1S-N500 & 35 & 225.5 & 2 & 120 & 500 & 2.22 & - & - & 800 & 1 & 277 \\
\hline 7 & & 1S-N548 & 35 & 225.5 & 2 & 120 & 548 & 2.43 & - & - & 800 & 1 & 277 \\
\hline 3 & \multirow{4}{*}{$\begin{array}{c}\text { B } \\
\text { (Number of legs) }\end{array}$} & 1S-NL2 & 35 & 225.5 & 2 & 120 & 262 & 1.16 & - & - & 800 & 1 & 277 \\
\hline 8 & & 1S-NL3 & 35 & 225.5 & 3 & 120 & 262 & 1.16 & - & - & 800 & 1 & 277 \\
\hline 9 & & 1S-NL4 & 35 & 225.5 & 4 & 120 & 262 & 1.16 & - & - & 800 & 1 & 277 \\
\hline 10 & & 1S-IC1 & 35 & 225.5 & 3 & 120 & 349 & 1.55 & 200 & 200 & 800 & 0.25 & 277 \\
\hline 11 & \multirow{4}{*}{$\begin{array}{c}\mathrm{C} 1 \\
\text { (Column aspect } \\
\text { ratio) }\end{array}$} & 1S-IC2 & 35 & 225.5 & 3 & 120 & 349 & 1.55 & 200 & 400 & 800 & 0.5 & 277 \\
\hline 12 & & 1S-IC3 & 35 & 225.5 & 3 & 120 & 349 & 1.55 & 200 & 800 & 800 & 1 & 277 \\
\hline 13 & & 1S-IC4 & 35 & 225.5 & 3 & 120 & 349 & 1.55 & 400 & 400 & 800 & 0.5 & 277 \\
\hline 14 & & 1S-IC5 & 35 & 225.5 & 3 & 120 & 349 & 1.55 & 600 & 600 & 800 & 0.75 & 277 \\
\hline 15 & \multirow{4}{*}{$\begin{array}{c}\text { C2 } \\
\text { (Support width) }\end{array}$} & 2S-SB1 & 28.8 & 240 & 3 & 120 & 334 & 1.39 & - & - & 200 & 0.25 & 277.86 \\
\hline 16 & & 2S-SB2 & 28.8 & 240 & 3 & 120 & 334 & 1.39 & - & - & 400 & 0.5 & 277.86 \\
\hline 17 & & 2S-SB3 & 28.8 & 240 & 3 & 120 & 334 & 1.39 & - & - & 600 & 0.75 & 277.86 \\
\hline 18 & & 2S-SB4 & 28.8 & 240 & 3 & 120 & 334 & 1.39 & - & - & 800 & 1 & 277.86 \\
\hline
\end{tabular}

A: Transverse spacing, B: Legs, C: Support Condition (1: Interior column, 2: Support width). d: effective depth of the beam (mm), n: number of the vertical component of the Steel plate, $s_{L}$ : center-to-center longitudinal spacing of shear reinforcement $(\mathrm{mm}), s_{w}$ : center-to-center transverse spacing of shear reinforcement (mm), $c_{x}$ : longitudinal width of the column (mm), $c_{y}$ : transverse width of the column $(\mathrm{mm}), b_{s}$ : transverse width of the support $(\mathrm{mm}), \kappa$ : shape function of support width ratio. 


\subsection{Test Setup}

Both the central column specimens and the simply supported specimens were loaded at two points. Their shear span was $750 \mathrm{~mm}$ and $900 \mathrm{~mm}$, respectively. Load was applied to each specimen at a rate of $2 \mathrm{~mm} / \mathrm{min}$ using a hydraulic jack with a maximum capacity of $5000 \mathrm{kN}$. Test setup and specimen details are shown in Figure 4.

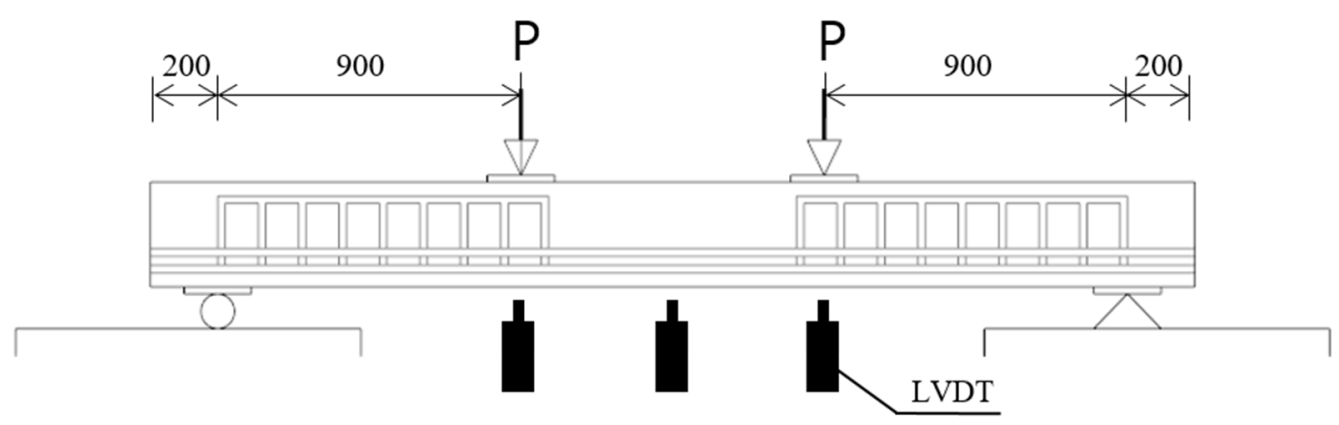

(a)

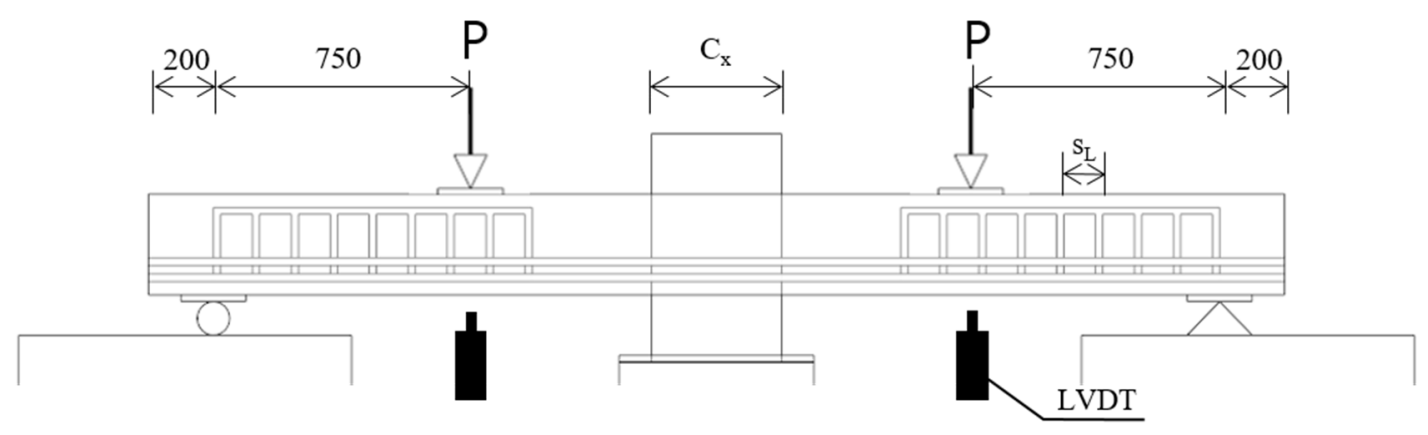

(b)

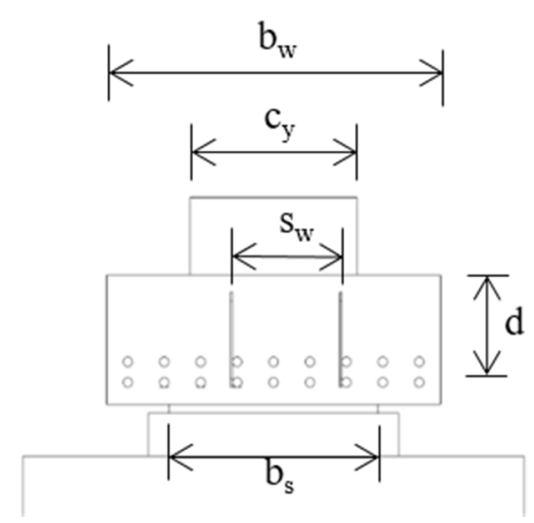

(c)

Figure 4. Test setup and dimensions: (a) general wide beam (groups A and B); (b) wide beam with column (group C1); (c) wide beam with different support width (group C2).

\section{Experimental Results and Discussion}

\subsection{Failure Mode and Crack Pattern}

All the specimens experienced shear failure. It was observed that initially flexural cracks in the middle of the beam. Under further loading, flexural cracks propagated toward the loading point and inclined cracks developed. The inclined cracks extended through the compressive zone, subsequently, final failure occurred. The crack patterns were asymmetrical and the wider shear cracks 
were observed as the transverse spacing increased. As the transverse spacing increased, the shear crack occurred and the number of strips of shear reinforcement through shear crack decreased as shown in Figure 5a-c. Figure 6 shows the cracking patterns of specimens for various number of shear reinforcement legs. Flexural cracks occurred at the middle of the beam. The effect to angle of shear crack according to the number of legs did not observed, but concrete splitting occurred in specimens with 2 and 3 legs, and wider diagonal cracks were observed. Also, the specimen with 4 legs of shear reinforcement had more flexural cracks than 2 legs as shown Figure 7. Cracks were observed near the column in specimen with narrow supports, while typical shear cracks were observed in specimen with wide support.

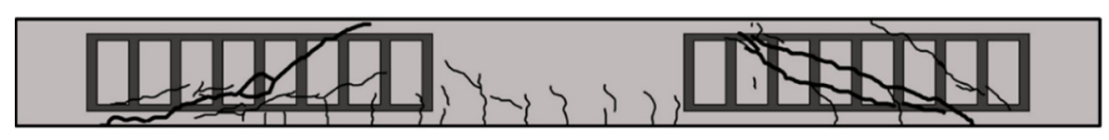

(a)

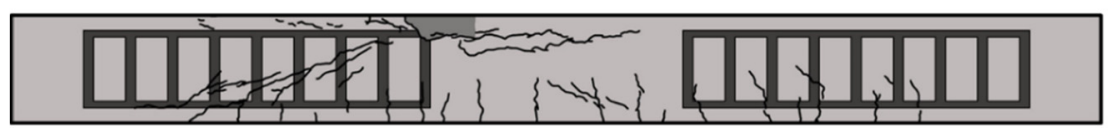

(b)

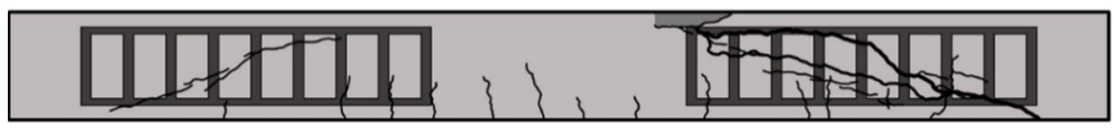

(c)
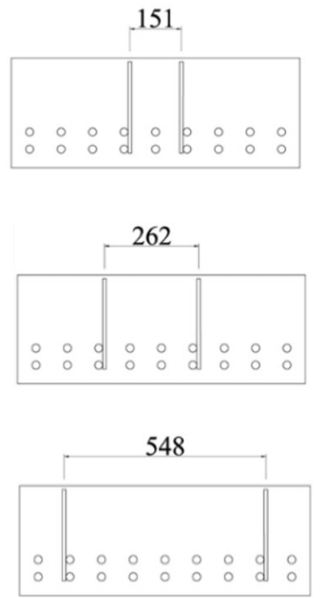

Figure 5. Crack pattern for various transverse spacing: (a) 1S-N151; (b) 1S-N262; (c) 1S-N548.

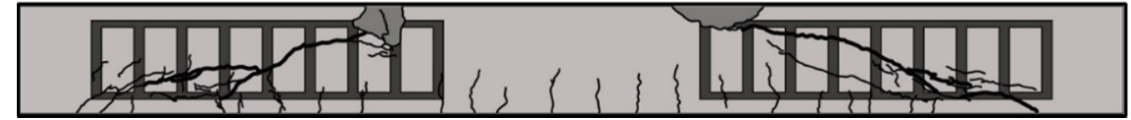

(a)

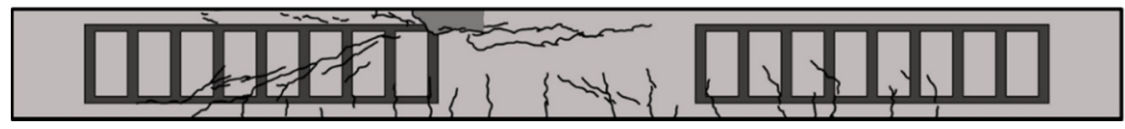

(b)

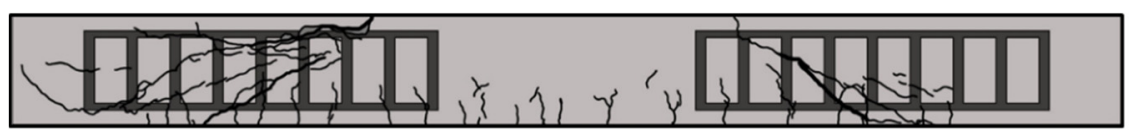

(c)
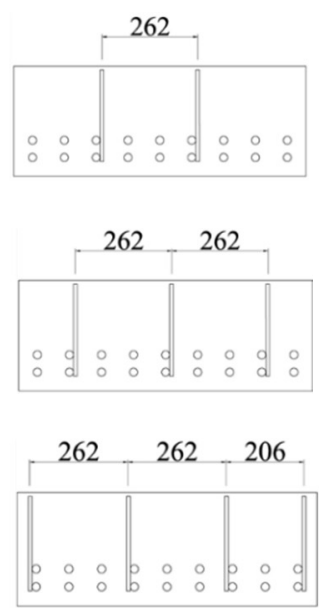

Figure 6. Crack pattern for various number of shear reinforcement legs: (a) 1S-NL2; (b) 1S-NL3; (c) 1S-NL4 


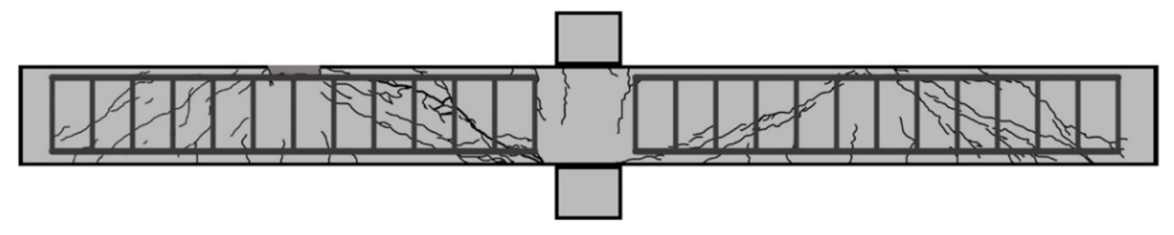

(a)

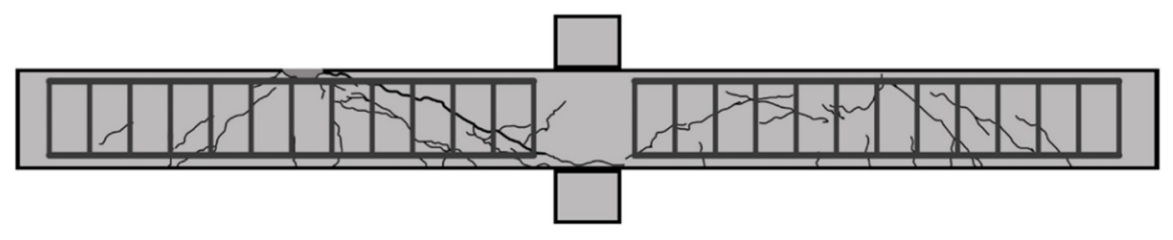

(b)
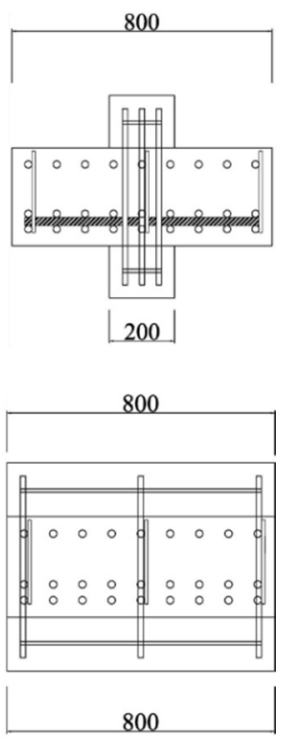

Figure 7. Crack pattern for various support width: (a) 2S-SB1; (b) 2S-SB4.

\subsection{Transverse Legs and Spacing}

Lubell et al. [4] did not consider the number of legs and the transverse reinforcement spacing independently. Therefore, the effect of the number of legs on the shear strength was not determined. Shuraim [5], however, considered the number of legs and the transverse reinforcement spacing independently. The shear capacity of specimens with four legs increased by $20 \%$ compared to those with two legs when the transverse reinforcement spacing ratio was 1.5.

The test results from Group A, with variable transverse reinforcement spacing, are presented in Table 3. For the specimens with transverse reinforcement spacing over 1.1d, shear strength decreased by a constant ratio. For 1S-N500 and 1S-N548, the $s_{w} / \mathrm{d}$ over 2, ACI 318-14 building code equation overestimated the shear capacity. The maximum failure load of 1S-N548 was only about $20 \%$ of the shear capacity predicted by the ACI 318-14 equation. This may be due to the poor contact conditions between the concrete and shear reinforcements.

Table 3. Test result.

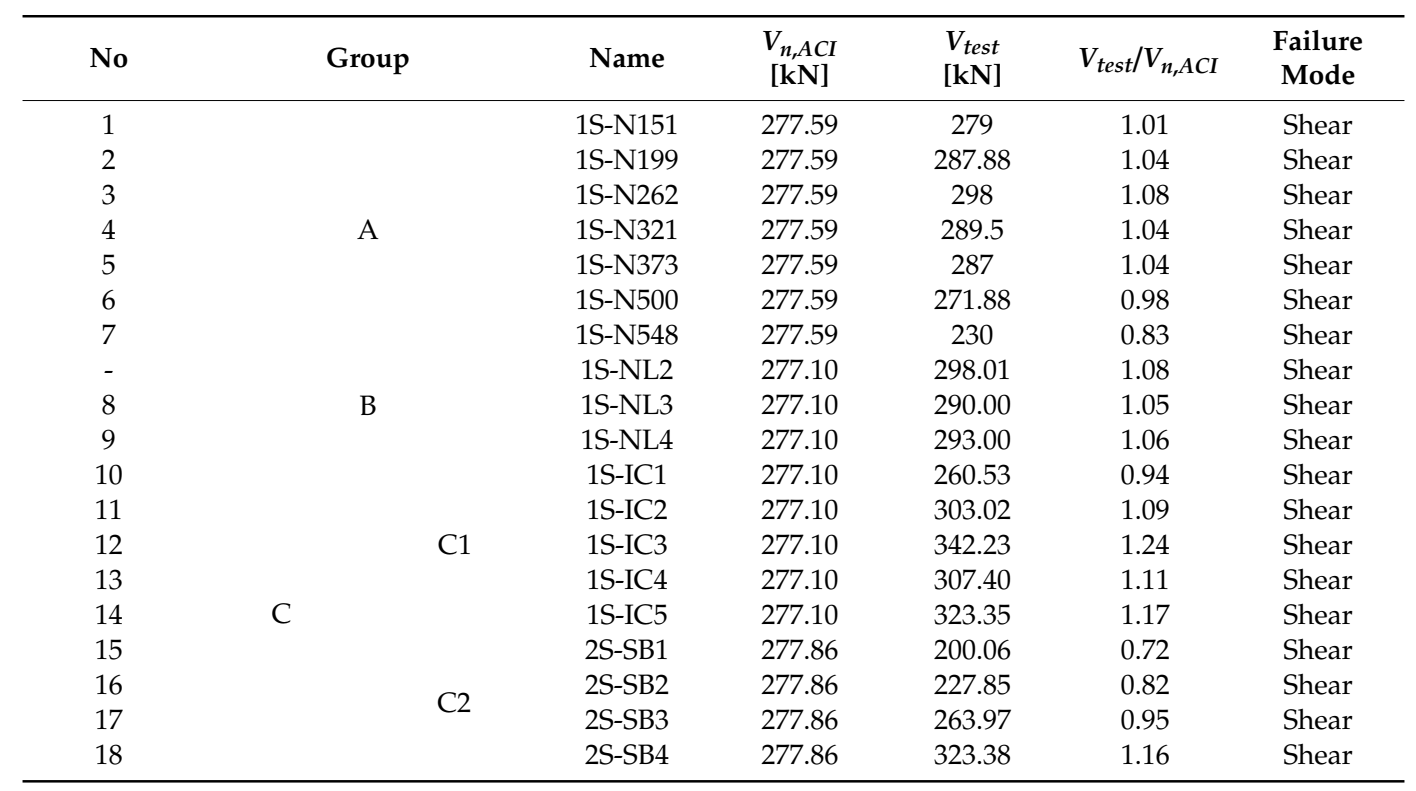


The test results of Group B, where the number of legs varies but the transverse reinforcement ratio of 1.16 remains the same, are presented in Table 3. As shown in Table 3, there was no significant influence of the number of legs on the relative shear strength. In general, shear reinforcement is placed on the path where shear cracks are observed to resist crack extension. Hence the reinforcement spacing should be determined based on the position where shear cracks occur. The number of legs did not have a significant effect on the shear capacity.

\subsection{Support Conditions}

Table 3 shows the test results of Group C, where the variable was the support conditions. For Group C1, the column was the support. The shear strength ratios $\left(V_{\text {test }} / V_{n, A C I}\right)$ for 1S-IC3 and 1S-IC1, which have support aspect ratios of 1 and 0.25 , respectively, decreased from 1.24 to 0.94 . For Group C2, with different support widths, the shear strength ratios $\left(V_{\text {test }} / V_{n, A C I}\right)$ for 2S-SB4 and 2S-SB1, which have support aspect ratios of 1 and 0.25 , respectively, decreased from 1.16 to 0.72 . As a result, the shear strength of the wide beams decreased when the transverse spacing of the support decreased, regardless of whether a column or support plate provides the support. The shear strength of specimens with an internal column was higher than specimens with different support conditions. This is because of column stiffness. In specimens 1S-IC1, 1S-IC4, and 1S-IC5, which had different support widths in the longitudinal direction, the shear strengths increased from $260.53 \mathrm{kN}$ to $323.35 \mathrm{kN}$ as the longitudinal width of the column $\left(c_{x}\right)$ increased to 200,400 , and $600 \mathrm{~mm}$. The shear strength of the 1S-IC2 and 1S-IC4 specimens increased 1.17 and 1.18 times based on the 1S-IC1 specimen that had a longitudinal and transverse width of $200 \mathrm{~mm}$; both the transverse width and the width in both directions increased by 2 . Therefore, this study considered the width of the transverse support as the main variable affecting shear strength. This is because it confirmed that increasing the width of the longitudinal support has little influence on the shear strength compared to the effect of the transverse support width.

\section{Proposal Equation for Capacity}

\subsection{Consideration of Transverse Spacing}

In this study, an experimental data of 27 specimens was composed to develop the shear strength equation for concrete wide beam. Tables 4 and 5 show the details of experiment performed by Lubell et al. [4] and Shuraim [5]. Two considerations were taken into account for the effect of transverse reinforcement spacing on the shear capacity. First, ACI 318-14 code assumes that the effects of shear reinforcement are equally distributed over the longitudinal reinforcement spacing, and does not consider shear capacities distributed in transverse reinforcement spacing. Therefore, the distribution of the shear reinforcement capacity in the transverse direction should be considered. Based on test results, the distribution ratio was determined by evaluating the effective depth $(d)$ to transverse reinforcement spacing $\left(s_{w}\right)$ ratio. The distribution ratio was defined in the longitudinal direction as $\Phi_{1}$ and in the transverse direction as $\Phi_{2}$. The shear strength contribution to the longitudinal direction decreased as the transverse reinforcement spacing increased. The summation of the shear capacity distribution ratios in the transverse and longitudinal directions cannot exceed 1 . Therefore, when $\phi_{1}$ is determined, $\phi_{2}$ is dependent on that value. The equations for calculating the distribution are described by Equations (11) and (12). Equation (11) is proposed as shown in Figure 8.

$$
\begin{gathered}
\Phi_{1}=-0.1\left(\frac{s_{w}}{d}\right)+1 \\
\Phi_{1}+\Phi_{2}=1
\end{gathered}
$$


Table 4. Details of Lubell's specimens.

\begin{tabular}{|c|c|c|c|c|c|c|c|c|c|c|c|c|c|c|}
\hline No & Name & $f_{c}^{f_{c}}$ & $\begin{array}{l}f_{y v} \\
{[\mathrm{MPa}]}\end{array}$ & $\begin{array}{c}d \\
{[\mathrm{~mm}]}\end{array}$ & $\begin{array}{c}A_{v} \\
{\left[\mathrm{~mm}^{2}\right]}\end{array}$ & $n$ & $\begin{array}{c}s_{L} \\
{[\mathrm{~mm}]}\end{array}$ & $\begin{array}{c}s_{w} \\
{[\mathrm{~mm}]}\end{array}$ & $s_{w} / d$ & $\begin{array}{c}c_{x} \\
{[\mathrm{~mm}]}\end{array}$ & $\begin{array}{c}c_{y} \\
{[\mathrm{~mm}]}\end{array}$ & $\begin{array}{c}b_{w} \\
{[\mathrm{~mm}]}\end{array}$ & $\kappa$ & $\begin{array}{c}V_{n, A C I} \\
{[\mathrm{kN}]}\end{array}$ \\
\hline 1 & AW4 & 39.9 & - & 506 & - & - & 300 & - & - & 305 & 305 & 1168 & 0.26 & 619.66 \\
\hline 2 & AW8 & 39.4 & - & 507 & - & - & 300 & - & - & 152 & 1169 & 1169 & 1.00 & 620.16 \\
\hline 3 & AX8 & 41 & - & 289 & - & - & 175 & - & - & 152 & 152 & 705 & 0.22 & 217.46 \\
\hline 4 & AX6 & 41 & - & 288 & - & - & 175 & - & - & 152 & 703 & 703 & 1.00 & 216.03 \\
\hline 5 & AW5 & 34.8 & 458 & 511 & 272 & 4 & 300 & 375 & 0.73 & 305 & 305 & 1170 & 0.26 & 802.50 \\
\hline 6 & AW7 & 35.8 & 458 & 512 & 272 & 4 & 300 & 370 & 0.72 & 152 & 1170 & 1170 & 1.00 & 807.52 \\
\hline 7 & AW2 & 39.3 & 452 & 507 & 400 & 2 & 300 & 1080 & 2.13 & 305 & 305 & 1172 & 0.26 & 929.55 \\
\hline 8 & AW6 & 43.7 & 452 & 509 & 400 & 2 & 300 & 1080 & 2.12 & 152 & 1170 & 1169 & 1.00 & 966.67 \\
\hline 9 & AW3 & 37.2 & 452 & 509 & 400 & 2 & 300 & 800 & 1.57 & 305 & 305 & 1165 & 0.26 & 909.54 \\
\hline 10 & $\mathrm{AX} 1$ & 42 & 458 & 289 & 136 & 2 & 175 & 625 & 2.16 & 152 & 703 & 703 & 1.00 & 322.31 \\
\hline 11 & $\mathrm{AX} 2$ & 42 & 600 & 286 & 103.2 & 2 & 175 & 625 & 2.79 & 152 & 703 & 703 & 1.00 & 318.36 \\
\hline 12 & AX3 & 42 & 613 & 285 & 116.1 & 3 & 175 & 350 & 1.23 & 152 & 707 & 707 & 1.00 & 333.54 \\
\hline 13 & AX4 & 42 & 625 & 285 & 103.2 & 4 & 175 & 235 & 0.82 & 152 & 698 & 698 & 1.00 & 319.91 \\
\hline 14 & AX5 & 41 & 458 & 283 & 136 & 2 & 175 & 470 & 1.66 & 152 & 697 & 697 & 1.00 & 311.23 \\
\hline
\end{tabular}

Table 5. Details of Shuraim's specimens.

\begin{tabular}{ccccccccccccccc}
\hline No & Name & $\begin{array}{c}f_{c} \\
{[\mathbf{M P a}]}\end{array}$ & $\begin{array}{c}f_{y v} \\
{[\mathrm{MPa}]}\end{array}$ & $\begin{array}{c}d \\
{[\mathrm{~mm}]}\end{array}$ & $\begin{array}{c}A_{v} \\
{\left[\mathbf{m m}^{2}\right]}\end{array}$ & $n$ & $\begin{array}{c}s_{L} \\
{[\mathrm{~mm}]}\end{array}$ & $\begin{array}{c}s_{w} \\
{[\mathrm{~mm}]}\end{array}$ & $s_{w w} / d$ & $\begin{array}{c}c_{x} \\
{[\mathrm{~mm}]}\end{array}$ & $\begin{array}{c}c_{y} \\
{[\mathbf{m m}]}\end{array}$ & $\begin{array}{c}\boldsymbol{b}_{w} \\
{[\mathrm{~mm}]}\end{array}$ & $\boldsymbol{\kappa}$ & $\begin{array}{c}V_{n, A C I} \\
{[\mathbf{k N}]}\end{array}$ \\
\hline 1 & S1-80 & 29 & 483 & 152 & 157 & 2 & 80 & 660 & 4.34 & 200 & 140 & 700 & 0.20 & 239.58 \\
\hline 2 & S2-80 & 29 & 483 & 152 & 157 & 2 & 80 & 440 & 2.89 & 200 & 140 & 700 & 0.20 & 239.58 \\
\hline 3 & S3-80 & 29 & 483 & 152 & 157 & 2 & 80 & 230 & 1.51 & 200 & 140 & 700 & 0.20 & 239.58 \\
\hline 4 & S1-75-1A & 28 & 465 & 149 & 201 & 2 & 75 & 660 & 4.43 & 200 & 140 & 700 & 0.20 & 277.67 \\
\hline 5 & S3-75-1 & 28 & 465 & 149 & 201 & 2 & 75 & 230 & 1.54 & 200 & 140 & 700 & 0.20 & 277.67 \\
\hline 6 & S13-75-1A & 28 & 465 & 149 & 201 & 4 & 75 & 230 & 1.54 & 200 & 140 & 700 & 0.20 & 277.67 \\
\hline 7 & S13-100-1 & 28 & 465 & 149 & 201 & 4 & 100 & 230 & 1.54 & 200 & 140 & 700 & 0.20 & 231.25 \\
\hline 8 & S13-125-1 & 28 & 465 & 149 & 201 & 4 & 125 & 230 & 1.54 & 200 & 140 & 700 & 0.20 & 203.39 \\
\hline 9 & S1-75-2 & 30 & 465 & 149 & 201 & 2 & 75 & 660 & 4.43 & 200 & 140 & 700 & 0.20 & 280.90 \\
\hline 10 & S3-75-2 & 30 & 465 & 149 & 201 & 2 & 75 & 230 & 1.54 & 200 & 140 & 700 & 0.20 & 280.90 \\
\hline 11 & S13-75-2 & 30 & 465 & 149 & 201 & 4 & 75 & 230 & 1.54 & 200 & 140 & 700 & 0.20 & 280.90 \\
\hline 12 & S13-100-2 & 30 & 465 & 149 & 201 & 4 & 100 & 230 & 1.54 & 200 & 140 & 700 & 0.20 & 234.48 \\
\hline 13 & S13-125-2 & 30 & 465 & 149 & 201 & 4 & 125 & 230 & 1.54 & 200 & 140 & 700 & 0.20 & 206.62 \\
\hline
\end{tabular}




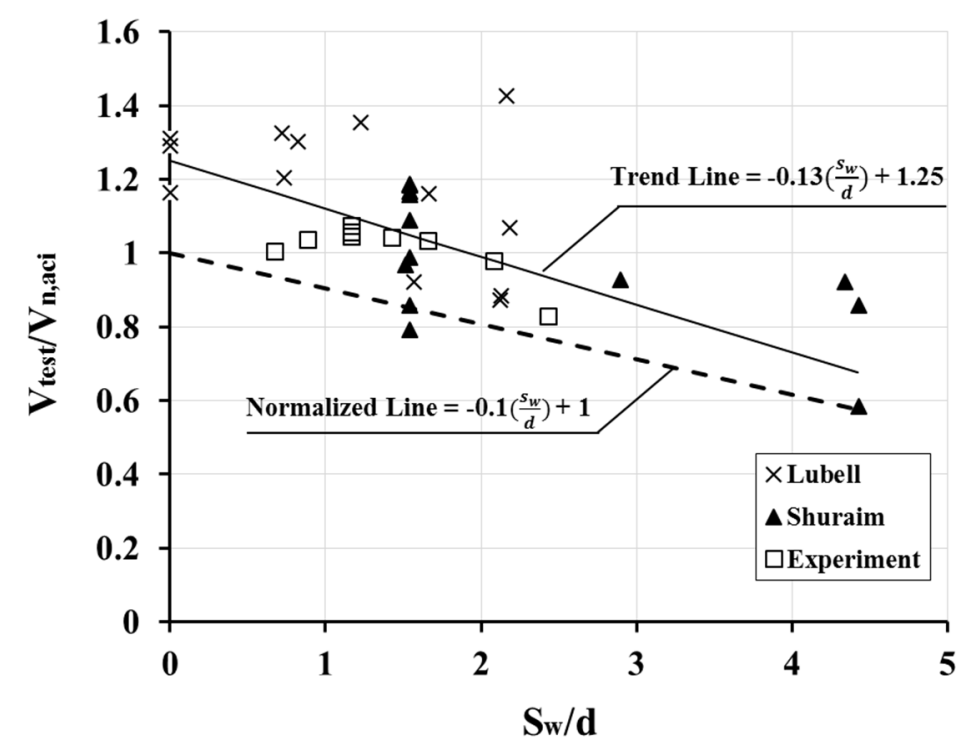

Figure 8. Distribution map of specimens with various transverse spacing.

\subsection{Support Conditions}

A reduction factor was proposed to consider the influence of support conditions on shear capacities. This is based on the experimental results from Group C. The test results showed a $70 \%$ specimen shear strength as $\kappa$ decreased from 1 to 0.25 . The reduction factors are given by Equations (13) and (14).

$$
\begin{gathered}
\beta=(0.4+0.6 \kappa)^{1 / 2 n} \\
\kappa=\min \left\{\left(b_{s} / b_{w}\right) \text { or }\left(c_{y} / b_{w}\right)\right\}
\end{gathered}
$$

\subsection{Proposed Shear Equation}

This study confirmed that the transverse spacing and support conditions are significant variables to determining the shear capacity in wide concrete beam. The two main variables and the number of legs, all of which are closely related to shear crack patterns, were considered when determining the proposed shear strength equation, which can be calculated by Equations (15)-(17).

$$
\begin{gathered}
V_{n, \text { Proposed }}=\beta\left(V_{c, A C I}+V_{s, \text { proposed }}\right) \\
V_{s, \text { proposed }}=\Phi_{1} V_{s, A C I}+\Phi_{2} V_{s w} \\
V_{s w}=\frac{A_{s} f_{y v} d}{s_{w}}
\end{gathered}
$$

\section{Evaluation of the Proposed Equation}

In this paper, the range of wide beams is determined as a beam width wider than the column width or beam width more than twice the beam height. This study's proposed equation was evaluated by comparing test results with results from ACI 318-14, Lubell et al. [4] and Shuraim [5]. Table 6 and Figure 9 show the comparisons results of 41 specimens except four non-reinforced specimens by Lubell et al. [4] Table 7 presents the mean and the standard deviation of the experimental value ratio using this study's shear strength equation. The error shown in Table 7 means that the number of situation, when ratio of the shear strength calculated by the equations to the test results is lower than 1. The shear strength calculated from ACI 318-14 shows a mean of 1.05, a standard deviation of 0.17 and a $43.9 \%$ error. ACI approach overestimates shear strength in case of wide transverse shear reinforcement spacing. This is because it does not consider the transverse reinforcement spacing or the 
support width. The shear strength calculated from the Lubell et al. [4] equation, which did not consider the transverse reinforcement spacing, and the Shuraim [5] equation, which did not consider the support plate width, shows means, and deviations of 1.22 and 0.20 and of 1.22 and 0.16 , respectively. The error from equation of Lubell et al. [4] and Shuraim [5] was $14.6 \%$ and $7.3 \%$. The shear strength calculated from this study's proposed equation shows a mean of 1.16 and a small standard deviation of 0.16 . The error observed from proposed equation was $12.2 \%$. These results indicate that by using this study's proposed shear strength equation, shear strength can be more effectively estimated since it considers significant variables affecting a concrete wide beam.

Table 6. Comparison of test results and equations.

\begin{tabular}{|c|c|c|c|c|c|c|c|c|c|c|c|}
\hline No. & Name & $\frac{V_{\text {test }}}{V_{n, A C I}}$ & $\frac{V_{\text {test }}}{V_{n, \text { Lubell }}}$ & $\frac{V_{\text {test }}}{V_{n, \text { Shuraim }}}$ & $\frac{V_{\text {test }}}{V_{n, \text { Proposed }}}$ & No. & Name & $\frac{V_{\text {test }}}{V_{n, A C I}}$ & $\frac{V_{\text {test }}}{V_{n, \text { Lubell }}}$ & $\frac{V_{\text {test }}}{V_{n, \text { Shuraim }}}$ & $\frac{V_{\text {test }}}{V_{n, \text { Proposed }}}$ \\
\hline 1 & AW5 & 1.2 & 1.54 & 1.2 & 1.3 & 22 & S13-100-2 & 1.19 & 1.56 & 1.41 & 1.357 \\
\hline 2 & AW7 & 1.33 & 1.33 & 1.32 & 1.331 & 23 & S13-125-2 & 1.17 & 1.53 & 1.33 & 1.316 \\
\hline 3 & AW2 & 0.88 & 1.13 & 1.02 & 1.077 & 24 & 1S-N151 & 1.17 & 1.17 & 1.15 & 1.01 \\
\hline 4 & AW6 & 0.87 & 0.87 & 1 & 0.919 & 25 & 1S-N199 & 1.21 & 1.21 & 1.26 & 1.05 \\
\hline 5 & AW3 & 0.92 & 1.18 & 1.02 & 1.102 & 26 & 1S-N262L2 & 1.25 & 1.25 & 1.37 & 1.098 \\
\hline 6 & $\mathrm{AX} 1$ & 1.17 & 1.5 & 1.17 & 1.502 & 27 & 1S-N321 & 1.22 & 1.22 & 1.38 & 1.077 \\
\hline 7 & $\mathrm{~A} \times 2$ & 1.2 & 1.55 & 1.2 & 1.124 & 28 & 1S-N373 & 1.21 & 1.21 & 1.41 & 1.077 \\
\hline 8 & $\mathrm{AX} 3$ & 0.87 & 0.87 & 1 & 1.385 & 29 & 1S-N500 & 1.14 & 1.14 & 1.39 & 1.038 \\
\hline 9 & $\mathrm{AX} 4$ & 1.33 & 1.33 & 1.32 & 1.313 & 30 & 1S-N548 & 0.97 & 0.97 & 1.2 & 0.889 \\
\hline 10 & AX5 & 1.29 & 1.29 & 1.29 & 1.2 & 31 & 1S-NL3 & 1.05 & 1.05 & 1.13 & 1.071 \\
\hline 11 & $\mathrm{~S} 1-80$ & 0.92 & 1.21 & 1.43 & 1.41 & 32 & 1S-NL4 & 1.06 & 1.06 & 1.14 & 1.082 \\
\hline 12 & $\mathrm{~S} 2-80$ & 0.93 & 1.22 & 1.32 & 1.272 & 33 & 1S-IC1 & 0.94 & 1.21 & 1.06 & 1.078 \\
\hline 13 & S3-80 & 0.97 & 1.27 & 1.19 & 1.212 & 34 & 1S-IC2 & 1.09 & 1.29 & 1.23 & 1.204 \\
\hline 14 & S1-75-1A & 0.58 & 0.77 & 0.97 & 0.932 & 35 & 1S-IC3 & 1.24 & 1.24 & 1.39 & 1.282 \\
\hline 15 & S3-75-1 & 0.79 & 1.04 & 1.01 & 1.003 & 36 & 1S-IC4 & 1.11 & 1.31 & 1.25 & 1.222 \\
\hline 16 & S13-75-1A & 0.99 & 1.3 & 1.28 & 1.151 & 37 & 1S-IC5 & 1.17 & 1.26 & 1.31 & 1.244 \\
\hline 17 & S13-100-1 & 1.16 & 1.52 & 1.39 & 1.327 & 38 & $2 \mathrm{~S}-2 \mathrm{~B} 1$ & 0.72 & 0.93 & 0.81 & 0.823 \\
\hline 18 & S13-125-1 & 1.18 & 1.56 & 1.36 & 1.337 & 39 & 2S-2B2 & 0.82 & 0.96 & 0.92 & 0.901 \\
\hline 19 & S1-75-2 & 0.86 & 1.13 & 1.42 & 1.364 & 40 & 2S-2B3 & 0.95 & 1.03 & 1.07 & 1.011 \\
\hline 20 & S3-75-2 & 0.86 & 1.13 & 1.09 & 1.085 & & & & & & \\
\hline 21 & S13-75-2 & 1.09 & 1.43 & 1.38 & 1.269 & 41 & 2S-2B4 & 1.16 & 1.16 & 1.31 & 1.205 \\
\hline
\end{tabular}

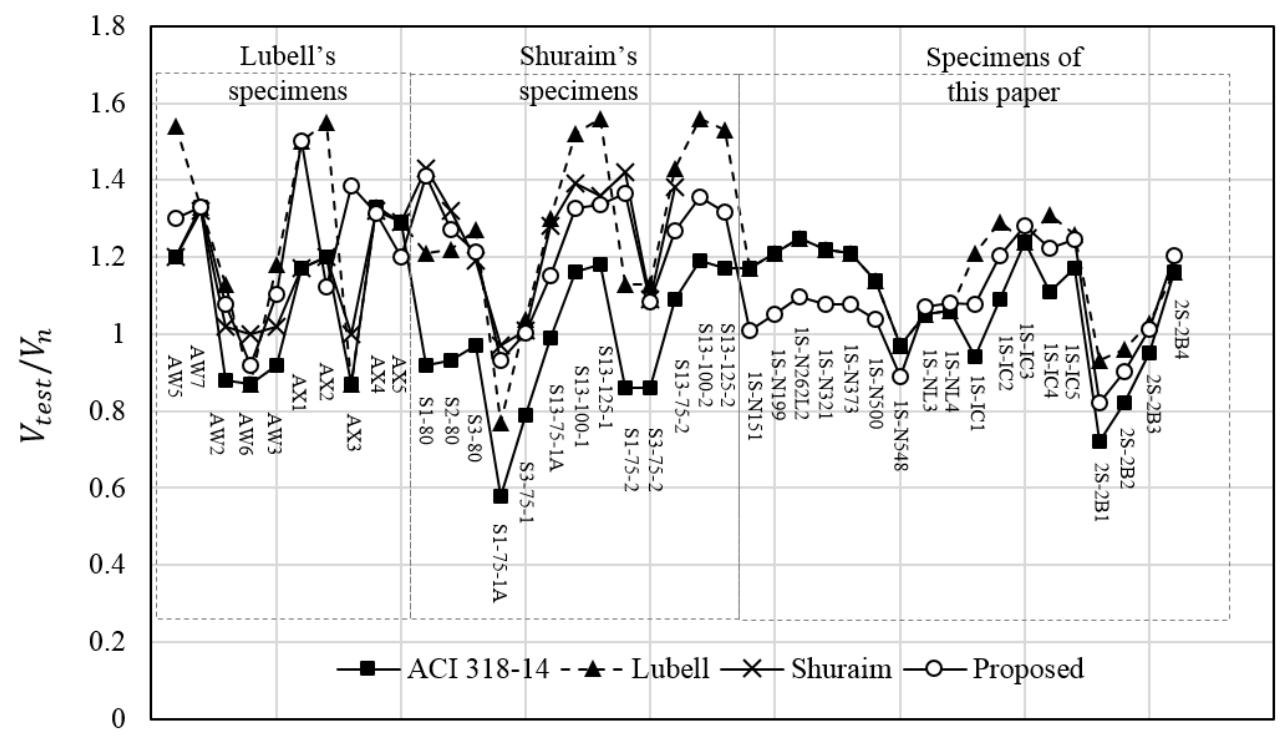

Figure 9. Comparison of shear equations with test results. 
Table 7. Comparison of shear equation's accuracy.

\begin{tabular}{cccc}
\hline Equation & Mean & SD & Error (\%) \\
\hline ACI 318-14 & 1.05 & 0.17 & 43.9 \\
\hline Lubell's & 1.22 & 0.20 & 14.6 \\
\hline Shuraim's & 1.22 & 0.16 & 7.3 \\
\hline Proposed & 1.16 & 0.16 & 12.2 \\
\hline
\end{tabular}

\section{Conclusions}

In this study, a new shear strength equation was developed using experimental results from transverse reinforcement spacing and support conditions for concrete wide beams. The following specific conclusions were drawn from this study:

1. The shear capacity decreased as the transverse reinforcement spacing increased. There was no significant effect of the number of legs on the shear strength when the transverse spacing was 1.1d.

2. The shear strength of the wide beam decreased as the transverse width of the support decreased, regardless of the support conditions; increasing the width of the longitudinal support was insignificant. This indicates that changing the transverse width rather than changing the longitudinal support width is more effective for determining shear capacity.

3. The proposed shear strength equation can better predict adequate shear strength for a wide beam than the equations described in ACI 318-14 and other researchers. This is possible by considering all the main variables that affect shear capacity.

Author Contributions: M.S.K. conceived the study concepts, designed and carried the experiment, analyzed the experimental results, and took charge of the entire manuscript; Y.H.L. and J.K. assisted with the integrity of the entire study, provided the crucial intellectual support, and revised the manuscript.

Funding: This work was supported by a National Research Foundation of Korea (NRF) grant funded by the Korean government (MSIT)(NRF-2017R1C1B1008928).

Conflicts of Interest: The authors declare no conflict of interest.

\section{References}

1. Leonhardt, F.; Walther, R. The Stuttgart shear tests, 1961. Cem. Concr. Assoc. Libr. 1961, 111, $49-54$.

2. Hsiumg, W.; Frantz, G.C. Transverse Stirrup Spacing in R/C Beams. J. Struct. Eng. 1985, 111, $353-362$. [CrossRef]

3. Anderson, N.S.; Ramirez, J.A. Detailing of Stirrup Reinforcement. ACI Struct. J. 1989, 86, 507-515.

4. Lubell, A.S.; Bentz, E.C.; Collins, M.P. Shear Reinforcement Spacing in Wide Members. ACI Struct. J. 2009, 106, 205-214.

5. Shuraim, A.B. Transverse Stirrup Configurations in RC Wide Shallow Beams Supported on Narrow Columns. J. Struct. Eng. 2012, 138, 416-424. [CrossRef]

6. Mohammadyan-Yasouj, S.E.; Marsono, A.K.; Abdullah, R.; Moghadasi, M. Wide Beam Shear Behavior with Diverse Types of Reinforcement. ACI Struct. J. 2015, 112, 199-208. [CrossRef]

7. Conforti, A.; Minelli, F.; Tinini, A.; Plizzari, G.A. Influence of Polypropylene Fibre Reinforcement and Width-to-Effective Depth Ratio in Wide-Shallow Beams. Eng. Struct. 2015, 88, 12-21. [CrossRef]

8. Conforti, A.; Minelli, F.; Plizzari, G.A. Influence of width-to-effective depth ratio on shear strength of reinforced concrete elements without web reinforcement. ACI Struct. J. 2017, 114, 995-1006. [CrossRef]

9. Khalil, A.E.H.; Etman, E.; Atta, A.; Baraghith, A.; Behiry, R. The Effective Width in Shear Design of Wide-shallow Beams: A Comparative Study. KSCE J. Civ. Eng. 2019, 23, 1670-1681. [CrossRef]

10. Conforti, A.; Tinini, A.; Minelli, F.; Plizzari, G.; Moro, S. Structural Applicability of Polypropylene Fibres: Deep and Wide-Shallow Beams subjected to Shear. ACI Spec. Publ. 2017, 310, 171-180. 
11. Navas, F.O.; Navarro, G.J.; Herdocia, G.L.; Serna, P.; Cuenca, E. An Experimental Study on the Shear Behaviour of Reinforced Concrete Beams with Macro-Synthetic Fibres. Constr. Build. Mater. 2018, 169, 888-899. [CrossRef]

12. Kim, D.J.; Kim, M.S.; Choi, J.H.; Kim, H.C.; Lee, Y.H. Concrete Beams with Fiber-Reinforced Polymer Shear Reinforcement. ACI Struct. J. 2014, 111, 903-912. [CrossRef]

13. ACI Committee 318. Building Code Requirements for Reinforced Concrete and Commentary (ACI 318-14); American Concrete Institute: Farmington Hills, MI, USA, 2014; p. 520.

14. ACI Committee 440. Guide for the Design and Construction of Structural Concrete Reinforced with Fiber-Reinforced Polymer Bars (ACI 440.1R-15); American Concrete Institute: Farmington Hills, MI, USA, 2015; p. 88.

15. Kim, H.C.; Kim, M.S.; Ko, M.J.; Lee, Y.H. Shear Behavior of Concrete Beams Reinforced with GFRP Shear Reinforcement. Int. J. Polym. Sci. 2015, 2015, 213583. [CrossRef]

(C) 2019 by the authors. Licensee MDPI, Basel, Switzerland. This article is an open access article distributed under the terms and conditions of the Creative Commons Attribution (CC BY) license (http://creativecommons.org/licenses/by/4.0/). 